\title{
Evolving Stable Behavior in a Spino-neuromuscular System Model
}

\author{
Stanley Gotshall \\ Department of Computer Science \\ University of Idaho \\ Moscow, ID \\ gots9018@uidaho.edu
}

\author{
Terence Soule \\ Department of Computer Science \\ University of Idaho \\ Moscow, ID \\ tsoule@cs.uidaho.edu
}

\begin{abstract}
This paper demonstrates the effectiveness of genetic algorithms in training stable behavior in a model of the spinoneuromuscular system (SNMS). In particular, we test the stability of trained instances of the model with respect to unfamiliar control signals and untrained forearm weights. The results show that small changes to the input frequency and forearm weight result in small changes in velocity, demonstrating that the system can reasonably accommodate unfamiliar circumstances. This type of stability is a critical feature for virtually any type of control system.
\end{abstract}

\section{Categories and Subject Descriptors}

I.2 [Computing Methodologies]: Artificial Intelligence

\section{General Terms}

Algorithms

\section{Keywords}

Neural Networks, Genetic Algorithms, Robotics

\section{INTRODUCTION AND EXPERIMENTS}

Neural networks in the spinal cord provide the body with a remarkably precise system for motor control. Muscles consist of thousands of muscle fibers that respond to electrochemical signals from the spinal cord to move and stabilize the body. Studies show that behavior of the primary motor cortex (M1) is correlated with arm position[4], acceleration[1], and target position[2]. Simulating these types of systems opens the door to developing prosthetic devices that interpret brain signals the same way the spinal cord does and designing robots with abilities comparable to humans. Designing this type of system also potentially makes it possible to test hypotheses regarding motor control, such as how motor control commands are encoded in the brain.

Our goal is to evolve a stable system capable of multiple tasks. We hypothesize that small changes to how the SNMS model is used, such as using slightly different input frequencies and forearm weights, will result in small changes in behavior. This would prove that a GA does not train the system to only respond to familiar inputs and tasks. Rather,

Copyright is held by the author/owner(s).

GECCO'08, July 12-16, 2008, Atlanta, Georgia, USA.

ACM 978-1-60558-130-9/08/07.

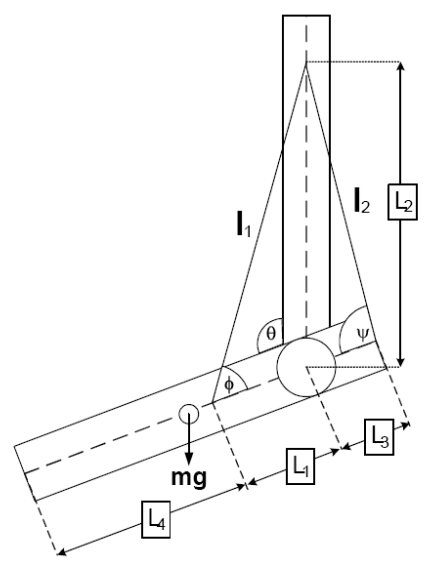

Figure 1: The SNMS joint model with a single degree of freedom.

that it produces a stable system that generalizes its behavior for a variety of tasks. The spino-neuromuscular system (SNMS) model used in these and previous[3] experiments consists of two groups of muscle fibers corresponding to the biceps and triceps (Figure 1). Each muscle fiber is controlled by a relatively small neural network that processes information from the muscle fibers and other feedback pathways.

The following experiments use a steady-state GA for training. The GA trains all parameters of the model and evaluates the fitness of potential solutions with equation

$$
F=-\sum_{\text {all } t}(\Theta(t)-\operatorname{target}(t))^{2}
$$

where $\Theta(t)$ is the angle between the movable forearm and the fixed upper arm segment at time $t$ and target $(t)$ is the target angle at time $t$. In these experiments the total fitness is the sum of each individual training case.

The first experiment involves training the model to move upward and downward at a single speed of $45 \frac{\mathrm{deg}}{\mathrm{sec}}$ with 3 different forearm weights. Each system is trained with forearm weights of $0.5,0.6$, and $0.7 \mathrm{~kg}$ (Figure 2), and tested on every weight in the closed interval $[0.4,0.8] \mathrm{kg}$ in $0.05 \mathrm{~kg}$ increments (Figure 3). The results in Figure 3 show that even with untrained weights the target trajectory is generally followed. Figure 3 also shows that the test case with $0.45 \mathrm{~kg}$ approaches the target's peak angle faster than the $0.4 \mathrm{~kg}$ test case, although the $0.4 \mathrm{~kg}$ case does move faster 


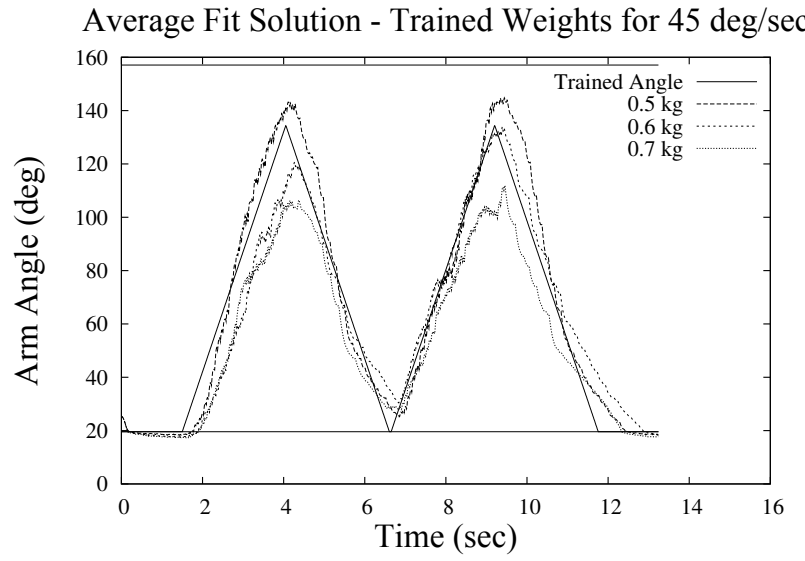

Figure 2: Arm motions of average fit sample with familiar forearm weights.

Average Fit Solution - Tests Weights for $45 \mathrm{deg} / \mathrm{sec}$

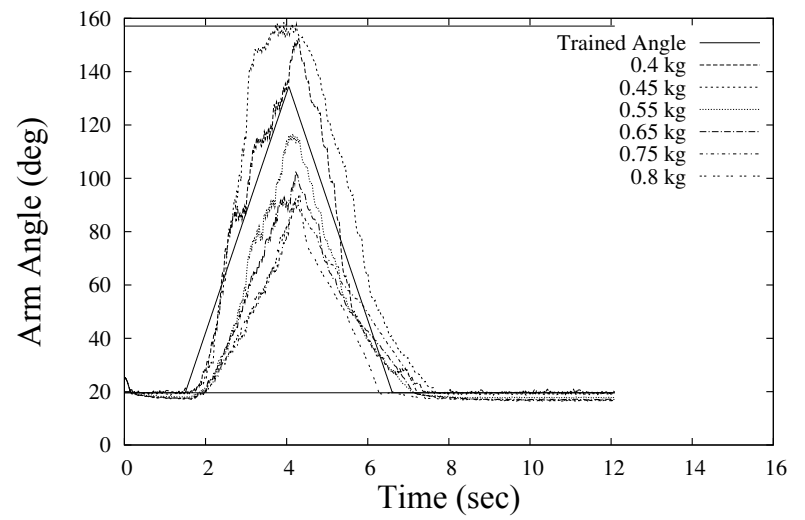

Figure 3: Arm motions of average fit sample with unfamiliar forearm weights.

Average Fit Solution - Altered Inputs for $45 \mathrm{deg} / \mathrm{sec}$

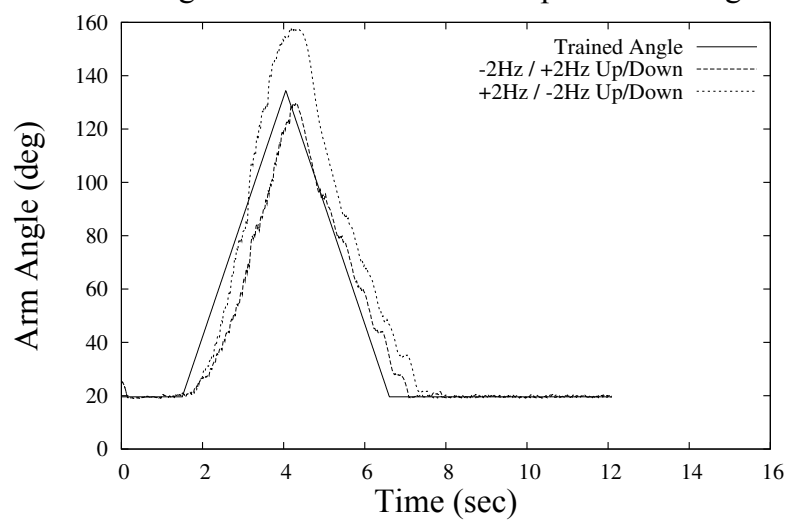

Figure 4: Test cases with constant forearm weight using $32 \mathrm{~Hz} / 18 \mathrm{~Hz}$ and $28 \mathrm{~Hz} / 22 \mathrm{~Hz}$ for up/down motion, respectively. than the $0.5 \mathrm{~kg}$ case. This indicates a nonlinear relationship between weight and velocity. The SNMS model includes feedback and inhibitory pathways that can account for this type of nonlinearity in biology.

The second experiment involves training the SNMS model to raise and lower the arm at $45 \frac{\mathrm{deg}}{\mathrm{sec}}$ and test the trained system on slightly modified input frequencies. The system is trained to achieve upward and downward motion with inputs of $30 \mathrm{~Hz}$ and $20 \mathrm{~Hz}$, respectively. Similarly to Figure 3 , Figure 4 shows that relatively small changes to trained input frequencies and weights result in small deviations from the target motion, which is successfully trained with $30 \mathrm{hz}$ and $20 \mathrm{hz}$, for upward and downward motion.

\section{CONCLUSIONS}

This paper demonstrates the stability of the SNMS system model with respect to untrained inputs and arm weights. The results show that controlling the system with unfamiliar input frequencies results in small to moderate variations in speed while still achieving relatively smooth motion. Similarly, testing the model with unfamiliar forearm weights results in stable and controlled motion at different speeds. In each test cases the motion remains relatively smooth and the arm returns to the stable resting point at the end of the simulation. In prosthetic and robotics applications it is important that performing unfamiliar tasks, such as lifting unfamiliar weights, does not result in erratic behavior. These results demonstrate the robustness of the SNMS model and advances the possibility of successfully developing more complex models and tasks for biologically-based control systems.

\section{REFERENCES}

[1] D. Flament and J. Hore. Relations of Motor Cortex Neural Discharge to Kinematics of Passive and Active Elbow Movements in the Monkey. Journal of Neurophysiology, 60:1268-1284, 1988.

[2] A. P. Georgopoulos, J. T. Lurito, M. Petrides, A. B. Schwartz, and J. T. Massey. Mental Rotation of the Neuronal Population Vector. Science, 243:234-236, 1989.

[3] S. Gotshall, K. Browder, J. Sampson, T. Soule, and R. Wells. Stochastic Optimization of a Biologically Plausible Spino-neuromuscular System Model: A Comparison with Human Subjects. Genetic Programming and Evolvable Machines, 8(4)355-380, 2007.

[4] R.E. Kettner, A.B. Schwartz, and A.P. Georgopoulos. Positional Gradients and Population Coding of Movement Direction from Various Movement Origins. Journal of Neuroscience, 8:2938-2947, 1988. 